\title{
Inclusão de gordura na alimentação de caprinos e seu efeito sobre o perfil lipídico no leite: Revisão
}

\author{
$\underline{\text { Natália Lívia de Oliveira Fonteles }}^{1 *} ; \underline{\text { Rafael Teixeira de Sousa }}^{2} ;$ Juliete de Lima Gonçalves $^{1}$; \\ $\underline{\text { Juliana dos Santos Rodrigues Barbosa }}^{3}$; Sueli Freitas dos Santos ${ }^{4}$; Marco Aurélio Delmondes \\ $\underline{\text { Bomfim }}^{5}$ \\ ${ }^{1}$ Alunos de doutorado do Programa de Pós Graduação em Zootecnia, Universidade Federal da Paraíba, Areia, \\ Paraíba. \\ ${ }^{2}$ Aluno de doutorado do Programa de Pós-graduação em Nutrição e Produção Animal, Faculdade de Medicina \\ Veterinária e Zootecnia, Universidade de São Paulo, Pirassununga, São Paulo. \\ ${ }^{3}$ Aluno de doutorado do Programa de Pós Graduação em Zootecnia Universidade Federal do Ceará, Fortaleza. \\ ${ }^{4}$ Doutora em Zootecnia na área de Nutrição Animal. \\ ${ }^{5}$ Pesquisador da Embrapa Caprinos e Ovinos, Sobral, Ceará. \\ *Autor para correspondências E-mail:natalia.livia26@gmail.com
}

\begin{abstract}
RESUMO. Objetivou-se com este trabalho fazer uma revisão acerca da importância da suplementação de fontes de lipídeos e seu efeito sobre a modificação do perfil lipídico do leite. A utilização de lipídios na dieta de ruminantes representa uma forma de atender as demandas energéticas, bem como uma estratégia de manipular o perfil de ácidos graxos do leite, aumentando a participação dos ácidos poli-insaturados e reduzindo os ácidos graxos saturados. Diversas fontes de lipídios estão sendo utilizadas nas dietas para ruminantes, sob forma de óleo vegetal, gordura protegidas ou inertes e sementes de oleaginosas, favorecendo assim o maior aporte de ácidos graxos poli-insaturados (linoleico e linolênico) na melhoria do perfil lipídico do leite. A agregação de valor aos produtos dos pequenos ruminantes representa uma das alternativas para ampliar as oportunidades do mercado do leite. Especialmente quando se agrega propriedades que associam nutrição e saúde, uma vez que há uma demanda crescente por alimentos funcionais e valorização destes produtos. $\mathrm{O}$ aumento do ácido linoléico conjugado (cis- 9 , trans - 11), reconhecido pelos seus efeitos anticarcinogênicos e antiaterogênicos torna o consumo de leite vantajoso para o consumidor pelos seus benefícios a saúde.
\end{abstract}

Palavras-chave: ácido linoleico, cabra, saúde humana

\section{Fat inclusion in goats feeding and its effect on the lipid profile in milk: Review}

\begin{abstract}
The aim of this work to review about the importance of supplementation of lipids sources and their effect on the modification of the milk fatty acid profile. The use of lipids in ruminant diet is a way to meet the energy requeriments, as well as a strategy to manipulate the profile of fatty acids in the milk, increasing the participation of polyunsaturated acids and reducing saturated fatty acids. Various sources of lipids are being used in ruminant diets in the form of vegetable oil, protected or inert fat and oil seeds, thus favoring the higher amount of polyunsaturated fatty acids (linoleic and linolenic) in improving the lipid profile of milk. Adding value to products of small ruminants is an alternative to expanding market opportunities milk. Especially when it adds properties that combine, nutrition and health, since there is a growing demand for functional foods and value of its products. The increase of conjugated linoleic acid (cis 9, trans - 11), recognized for its anticarcinogenic and anti-atherogenic effects makes the consumption of milk advantageous to the consumer for their health benefits.
\end{abstract}

Keywords: goat, human health, linoleic acid 


\section{Introdução}

O leite caprino é um dos alimentos com composição nutritiva de grande importância (proteína, gordura, cálcio, fósforo e vitaminas), além disso, pode ser fonte de componentes com capacidade de reduzir o surgimento de doenças, ou seja, alimento com potencial funcional, que além de nutrir, proporciona efeito benéfico à saúde.

No Brasil, o leite de cabra e seus derivados são comercializados a um valor superior ao leite de vaca quando comparado a outros países. Tal diferença pode chegar até $220 \%$ (Cordeiro \& Cordeiro, 2006). Este é um dos aspectos que reduz a competitividade deste produto $\mathrm{e}$ as oportunidades de ampliação de mercado. A agregação de valor aos produtos dos pequenos ruminantes representa uma das alternativas para ampliar as oportunidades do mercado do leite. Especialmente quando se agrega propriedades que associam nutrição e saúde, uma vez que há uma demanda crescente por alimentos funcionais e valorização destes produtos.

A suplementação lipídica em dietas para ruminantes visa aumentar sua densidade energética, melhorar a utilização de nutrientes e favorecer a participação de determinados ácidos graxos na composição do leite (Eifert et al., 2006, Corradini et al., 2013, Corradini et al., 2014). Além disso, a utilização de lipídeos contribui na redução da metanogênese e do incremento calórico. Entretanto, por interferir negativamente na digestão da fibra, a adição de lipídeos tem sido limitada a aproximadamente $5 \%$ ou menos da matéria seca do total dietético (Palmquist \& Jenkins, 1980).

Pesquisas vêm sendo desenvolvidas mediante uma alimentação diferenciada oferecida às cabras leiteiras, com o intuito de modificar o perfil dos ácidos graxos presentes no leite e assim agregar valor ao leite pelas moléculas com potencial funcional como é o caso do ácido linoléico conjugado CLA (cis- 9, trans-11).

O objetivo desta revisão foi abordar os principais aspectos relacionados ao efeito das fontes lipídicas sobre a composição do leite de cabra.

\section{Fontes de lipídios na alimentação}

A suplementação lipídica é utilizada para aumentar a densidade energética da dieta de ruminantes na tentativa de reduzir o balanço energético negativo, evitando a manifestação de distúrbios metabólicos, melhorando o desempenho da lactação e reprodução. De acordo com Palmquist (1989), existem inúmeras fontes de lipídeos que podem ser adicionadas em dietas para ruminantes, tais como sementes inteiras de oleaginosas (soja, girassol, algodão, canola etc.), óleos e gorduras livres (óleos vegetais, sebo, óleo reciclado de cozinha, óleos de peixes, misturas de óleos vegetais e animais) e gorduras especiais "protegidas" (sais de cálcio de ácidos graxos).

Algumas fontes de lipídeos podem ser classificadas como: ácidos graxos insaturados quando possui uma ou mais duplas ligações entre os carbonos e ácidos graxos saturados quando tem apenas ligações simples entre os carbonos. Assim, as fontes como os grãos de oleaginosas são considerados altamente insaturados, e o sebo como moderadamente insaturado. O grau de insaturação pode influenciar no metabolismo microbiano no rúmen e, consequentemente, no perfil de ácidos graxos do leite. Na tabela 1 podese observar a composição de ácidos graxos presente em diferentes fontes de lipídeos.

\section{Sais de cálcio de ácidos graxos}

Os ácidos graxos complexados com cálcio também chamados de "gordura protegida" consistem em uma fonte de ácidos graxos insaturados (ácido linoléico e linolênico protegido), que ao serem ingeridos pelos ruminantes passam intactos pelo rúmen e são metabolizados no intestino, onde há melhor aproveitamento de suas características particulares. Sua utilização em dietas para ruminantes visa diminuir a biohidrogenação ruminal de ácidos graxos insaturados (Tamminga \& Doreau, 1991).

Uma importante fonte comercial de gordura protegida é o Megalac ${ }^{\circledR}$, Magnapac ${ }^{\circledR}$, sais de cálcio de CLA, um sal de cálcio de ácidos graxos de cadeia longa com alta densidade energética, que contém altas concentrações de ácido linoléico $(42,0 \%)$ e ácido linolênico $(3,0 \%)$, e sua utilização em dietas para ruminantes visa atender às necessidades nutricionais para lactação e ganho de peso condizente com alto padrão genético dos animais (Jenkins, 1993). Um efeito desejável do uso de gorduras protegidas em dietas para ruminantes é a possibilidade de modificar a composição lipídica dos produtos alimentícios resultantes como a carne e o leite. Nesse sentido, (Jenkins \& McGuire, 2006) 
compararam publicações em que foram utilizadas fontes de gorduras protegidas e dieta controle, mostrando no leite produzido com gordura protegida, maior teor de ácidos oléico e linoléico.

\section{Óleo e gorduras}

O óleo vegetal é uma gordura proveniente da extração das sementes, bem como de outras partes da planta. Esse tipo de gordura é formado por triglicerídeos, resultante da combinação de três moléculas de ácidos graxos e uma molécula de glicerol. Os ácidos graxos são compostos por ácidos carboxílicos com cadeias hidrocarbonadas e seu comprimento pode variar de 4 e 36 carbonos. São classificados em ácidos graxos insaturados com ligações duplas nas cadeias de carbono e ácidos graxos saturados com ligações simples (Kozloski, 2011). As fontes mais comuns de óleos vegetais são: o de milho, algodão, soja, oliva, girassol, canola, amendoim e arroz. As fontes de gorduras, a maioria é de origem animal, sendo que as mais comuns são: sebo, banha e gordura de aves.

Tabela 1. Principais ácidos graxos contidos em algumas fontes de lipídeos

\begin{tabular}{|c|c|c|c|c|c|}
\hline \multirow[b]{2}{*}{ Fonte de Lipídeo } & \multicolumn{5}{|c|}{ Ácido Graxo } \\
\hline & $\begin{array}{c}\text { C16:0 } \\
\text { Palmítico }\end{array}$ & C18:0 Esteárico & $\begin{array}{l}\text { C18:1 } \\
\text { Oleico }\end{array}$ & $\begin{array}{c}\text { C18:2 } \\
\text { Linoleico }\end{array}$ & $\begin{array}{c}\text { C18:3 } \\
\text { Linolênico }\end{array}$ \\
\hline Sebo & 26 & 19 & 40 & 5 & 1 \\
\hline Gordura amarela & 21 & 11 & 44 & 14 & 3 \\
\hline Graxa branca $^{1}$ & 24 & 11 & 48 & 12 & 1 \\
\hline Booster Fat ${ }^{2}$ & 25 & 22 & 45 & 2 & - \\
\hline Megalac; EnerG-II ${ }^{2}$ & 51 & 4 & 35 & 8 & - \\
\hline Óleo de canola & 4 & 2 & 52 & 25 & 13 \\
\hline Óleo de algodão & 25 & 3 & 17 & 54 & - \\
\hline Óleo de linhaça & 5 & 3 & 20 & 16 & 55 \\
\hline Óleo de cártamo & 7 & 2 & 9 & 80 & $<1$ \\
\hline Óleo de soja & 8 & 3 & 24 & 58 & 8 \\
\hline Óleo de girassol & 6 & 4 & 20 & 66 & $<1$ \\
\hline Óleo de peixe (Menhaden) ${ }^{3}$ & 17 & 5 & 7 & 1 & 1 \\
\hline
\end{tabular}

${ }^{1}$ Onetti et al. (2001). ${ }^{2}$ Fontes comercias de gordura, parcialmente inertes no rúmen (Church \& Dwight Co., Virtus Nutrition). ${ }^{3}$ Também contém 10\% C16:1, 11\% C20:5 e 12\% C22:6.

As fontes de óleo vegetal são consideradas altamente insaturadas e, portanto, o grau de insaturação pode influenciar no metabolismo microbiano no rúmen e, consequentemente, no perfil de ácidos graxos do leite. Os ácidos graxos linoléico (C18:2) e ácido oléico (C18:1), predominam no óleo do girassol, milho, soja e algodão (ANVISA, 2010).

A suplementação de óleo vegetal na alimentação de ruminantes deve estar entre 3\% e $5 \%$ para não interferir na fermentação ruminal e consequentemente acarretar uma redução na digestibilidade dos nutrientes, principalmente da fibra (Palmquist \& Jenkins, 1980, Maia et al., 2010). Isto em decorrência do efeito físico sobre as partículas alimentares mediante ao encapsulamento tornando indisponível para a adesão bacteriana. Além disso, ácidos graxos insaturados são tóxicos para as bactérias celulolíticas. A toxicidade parece estar relacionada com o aumento da fluidez da membrana celular perdendo a permeabilidade seletiva e assim reduzindo a capacidade de regulação do pH intracelular e captação de nutrientes (Jenkins, 1993, Maia et al., 2010).

Segundo Van Soest (1994), as bactérias ruminais não são tolerantes aos lipídios, principalmente aos ácidos graxos insaturados. Kozloski (2011) ressalta ainda que problemas na degradação da fibra podem ocorrer devido à 
diminuição da capacidade de aderência das bactérias ruminais a partícula, pois a degradação de qualquer componente da dieta está associada à capacidade de aderência das células bacterianas ao produto de degradação e que estes mecanismos de aderência envolvem a participação de moléculas de natureza protéica e lipídica presente na superfície externa da célula bacteriana.

Principalmente nos últimos anos, pesquisas vêm sendo realizadas mediante o uso de fonte de óleo vegetal na alimentação de animais leiteiros, com o propósito de aumentar o teor de CLA no perfil lipídico da gordura do leite. Dessa maneira, podem trazer benefícios à saúde humana em virtude dos efeitos positivos desse isômero (Williams, 2000). A adição de fontes lipídicas ricas em ácido linoléico na alimentação, reconhecidamente resulta em mudanças na composição dos ácidos graxos do leite e podendo elevar o teor de CLA (Chilliard et al., 2003).

\section{Biohidrogenação e síntese de CLA}

A composição dos ácidos graxos presentes na circulação que são destinados à glândula mamária, segundo Tanaka (2005)sofre influência do processo de biohidrogenação (Figura 1).

A gordura proveniente da dieta é rapidamente transformada pelos microrganismos ruminais a partir de dois processos: a lipólise e a biohidrogenação. A lipólise é responsável pela hidrólise dos lipídeos esterificados da deita, pela ação de lipases microbianas extracelulares, que liberam os ácidos graxos livres e permite que o glicerol seja utilizado para produção de ácidos graxos de cadeia curta. Todavia, as bactérias não são capazes de aproveitar esses ácidos graxos como fonte de energia por serem compostos bastante reduzidos, mas elas podem incorporar parte na sua membrana citoplasmática (Demeyer

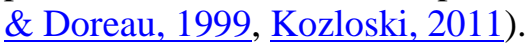

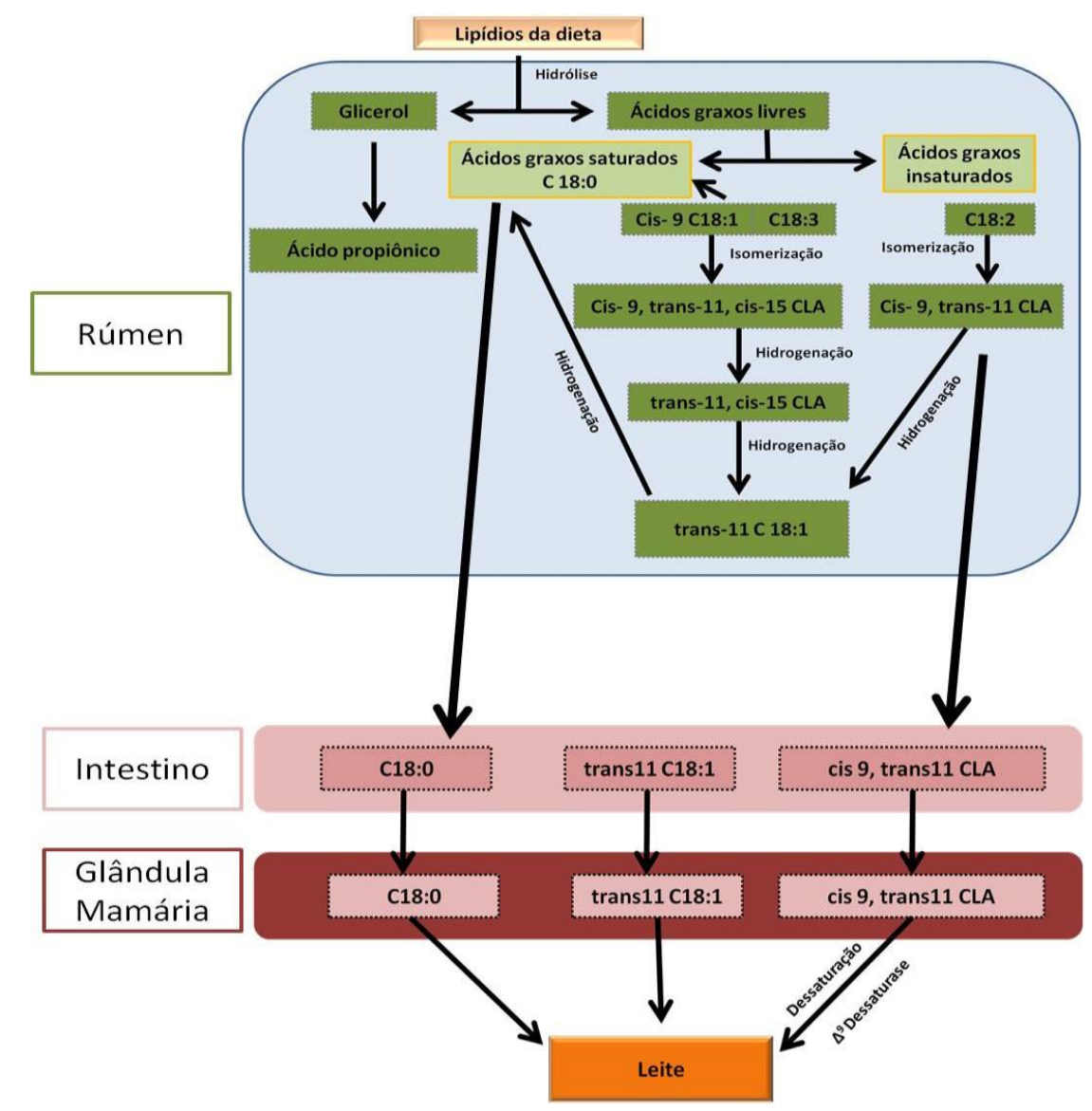

Figura 1. Metabolismo dos lipídios e origem do ácido linoléico conjugado no leite. Fonte: Adaptado de $\underline{\text { Tanaka }}$ $\underline{(2005)}$.

Os ácidos graxos resultantes do processo da lipólise passam por um processo conhecido como biohidrogenação ruminal, alterando esses ácidos graxos livres pela adição de hidrogênio no lugar 
das duplas ligações, transformando as ligações insaturadas em saturadas (Kozloski, 2011). Essa ação é realizada pelas bactérias ruminais, sendo a Butyrivibrio fibrisolvens a espécie mais conhecida (Kepler et al., 1966).

As bactérias que realizam a biohidrogenação são divididas em dois grupos: A e B. No rúmen as bactérias do grupo A são mais abundantes do que as bactérias do grupo B. O grupo A transforma o ácido linoléico (C18: 2) no ácido vacênico (C18: 1-trans -11). O grupo B reduz o ácido vacênico para o ácido esteárico (Demeyer

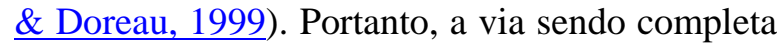
favorece a formação do ácido esteárico (C18: 0), tal mecanismo seria uma defesa contra os ácidos graxos insaturados por serem tóxicos as bactérias (Maia et al., 2010).

A manipulação da biohidrogenação ruminal pela suplementação de fontes de óleo vegetal ricos em ácidos graxos insaturados na dieta (C18:2) é uma estratégia alimentar que favorece um maior escape de intermediários (CLA e ácido vacênico) antes que a conversão a ácido esteárico seja completada (Bessa et al., 2000, Bomfim et al., 2011).

A etapa inicial da ação desses microrganismos sobre os lipídios poliinsaturados (C18:2 cis-9, trans-12) inicia-se pela isomerização cis-9, trans12 para cis -9 , trans-11 e posterior redução para C18: 1 trans-11(ácido vacênico). A partir dessa etapa as bactérias do grupo B realizam a ação de hidrogenar o $\mathrm{C}$ 18:1 trans- 11 no ácido esteárico (C 18:0) (Demeyer \& Doreau, 1999). Portanto, quando ocorre um aumento do acúmulo desse isômero (trans-11), essa etapa de hidrogenação começa a ficar ineficiente, favorecendo um maior escape de trans -11. O ácido vacênico (C18:1 trans -11) serve como substrato para síntese endógena de CLA (cis-9, trans- 11) na glândula mamária pela ação da enzima delta-9 desaturase sobre o trans-11 advindo da biohidrogenação incompleta (Griinari et al., 1999, Corl et al., 2001).

De acordo com Neves et al. (2009) a biohidrogenação ruminal pode ser evitada com o uso de métodos de proteção dos ácidos graxos no rúmen, sendo as principais formas: o fornecimento de grãos inteiros de oleaginosas com liberação lenta da gordura, uso sais de cálcio de ácidos graxos (gordura protegida), aplicação de técnicas de processamentos térmicos ou ainda a utilização de ionóforos que modifica a microbiota ruminal. Além disso, estudos vêm demonstrando a inibição da última etapa da biohidrogenação e acúmulo do ácido vacênico e uma redução do ácido esteárico pelo efeito inibitório do tanino sobre as bactérias do grupo B que são responsáveis por realizar a última etapa da biohidrogenação, ou seja, de C18:1 trans-11 para C18:0 (Demeyer \& Doreau, 1999). Essa atividade pode ser benéfica, uma vez que a inibição da última etapa do processo de biohidrogenação ruminal acumula os intermediários, dentre os quais o CLA e seu precursor para síntese endógena (C18:1 trans-11) (Vasta et al., 2009a, Vasta et al., 2009b, KhiaosaArd et al., 2009, Patra \& Saxena, 2010).

Experimentos in vitro demonstraram um efeito do tanino sobre a biohidrogenação ruminal por inibir a atividade dos microrganismos ruminais, favorecendo o acúmulo de ácido vacênico e uma redução do ácido esteárico (Vasta et al., 2009a, Vasta et al., 2009b, Khiaosa-Ard et al., 2009). No entanto, experimentos in vivo com taninos sobre seu efeito na biohidrogenação ruminal e modificação da composição da carne e leite rico em CLA, são contraditórios. Segundo Toral et al. (2011) não verificaram alteração importante no perfil dos ácidos graxos para os ácidos graxos poli-insaturados, principalmente do CLA (cis-9, trans-11) do leite pela adição de extrato de tanino com óleo de girassol na deita de ovelhas em lactação quando comparada a dieta controle que continha óleo de girassol. Os autores sugeriram que possivelmente a dose utilizada e o tipo de taninos (1:1 quebracho tanino condensado e extrato de tanino hidrolisável), ou ambos, podem ter sido responsáveis por não modificar o perfil de ácidos graxos no leite pelo aumento do ácido rumênico.

OCLA refere-se a uma combinação de isômeros geométricos (cis, cis; cis, trans; trans, cis e trans, trans) e posicionais (cis-8, cis-10; cis9, cis - 11; cis-10, cis-12 e cis-11, cis-13) do ácido linoléico (18:2) com duas duplas ligações conjugados, ou seja, separadas por ligações simples carbono-carbono, enquanto que o ácido linoléico (C18:2 cis-9, cis-12) apresenta as duplas ligações separadas por um grupo metileno (Bessa et al., 2000).

Apesar de existirem diversos isômeros do CLA, o (cis-9, trans-11) tem despertado grande interesse em função dos seus efeitos biológicos, podendo ser encontrado na carne e, principalmente no leite dos ruminantes (Pariza et al., 2001). A principal funcionalidade do CLA 
(cis-9, trans-11) está relacionada com seu efeito anticarcinogênica, essa foi à primeira característica a atrair interesse (Parodi, 1996).

Pesquisas utilizando diferentes modelos animal têm relacionado o CLA a vários benefícios a saúde. Ip et al. (1991), demonstraram que $0,1 \%$ de CLA na dieta de ratos com incidência de câncer induzido foi suficiente para reduzir tumores na glândula mamária. Por sua vez Lee et al. (1994) observaram o efeito do CLA sobre a aterosclerose em coelhos alimentados com uma dieta de 0,5 g de CLA que mostrou menor circulação de LDL colesterol. O LDL colesterol é conhecido como colesterol "mal", responsável pela formação dos ateromas, isto é, placas que se formam na parede dos vasos. Tais efeitos positivos atribuídos ao CLA (cis-9, trans-11), podem favorecer a saúde humana (Williams, 2000).

\section{Efeito da suplementação lipídica sobre a composição do leite de cabra}

A suplementação com diversas fontes de gordura resulta em aumento do teor de gordura no leite de cabras e de forma contrária ao que ocorre com bovinos. A diferença entre essas duas espécies quanto ao comportamento da suplementação de fonte lipídica está relacionada com a maior taxa de passagem observada em cabras, diminuindo assim o efeito das fontes de lipídios que diminuíram a lipogênese na glândula mamária, aumentando a gordura do leite de cabras (Chilliard et al., 2003).

No leite caprino, a gordura é o componente mais variável e é afetado por muitos fatores, incluindo genética, estado fisiológico e meio ambiente. No entanto, a gordura do leite é especialmente sensível à nutrição, proporcionando uma ferramenta prática para alterar a sua produção e composição (Harvatine et al., 2009). A alimentação dos caprinos leiteiros pode ser uma aliada importante para a manipulação da produção e o perfil de ácidos graxos do leite pela utilização de fontes de lipídios que aumentam de forma natural o CLA e diminuem o teor de gordura no leite.

Do ponto de vista dos produtores, a gordura do leite de cabra representa um componente de maior importância na determinação de sua qualidade nutricional e comercial, pois esses componentes estão envolvidos tanto na produção como na qualidade de queijos e estão diretamente relacionados à coloração e ao sabor de produtos lácteos (Delacroix-Buchet \& Lamberet, 2000).

A vantagem nutricional do leite de cabra em relação ao de vaca consiste no menor tamanho dos glóbulos de gordura, que resulta em produtos mais facilmente digestíveis. Além disso, aproximadamente $20 \%$ dos ácidos graxos do leite de cabra são de cadeia curta (C4:0 - C12:0) e de rápida digestão (Jenness, 1980).

Ao estudar o efeito da adição de 9 e $12 \%$ de gordura protegida rica em ácidos graxos poliinsaturados (PUFAs). Sanz Sampelayo et al. (2002) verificaram uma diminuição na proporção total de ácidos graxos saturados. Esses autores ainda relataram um aumento significante nas proporções de C14:1, C16:1, C18:2, C18:3,C20:2 e decréscimo de C18:0. Os resultados indicaram que a atividade ruminal não foi afetada pelo nível de adição de gordura, uma vez que não houve diminuição na proporção dos ácidos graxos até 14 átomos de carbono, que são provenientes da síntese de novo e, portanto, da concentração molar do acetato resultado da digestão das fibras no rúmen. Assim, presume-se que é possível, a partir da utilização de suplementos concentrados formulados com óleos que apresentem conteúdo elevado de ácido linoléico, obter teores elevados de ácidos graxos poliinsaturados, especialmente o CLA na gordura do leite caprino.

Bernard et al. (2009) em estudo avaliando o efeito de dietas com óleos vegetais concluíram que os óleos vegetais na dieta realçam a síntese da gordura de leite, alteram a composição de ácido graxo do leite e inibem especificamente a atividade mamária de estearoil-Coezima A dessaturase na cabra. Além disso, o regulamento do lipogênese mamária em resposta aos óleos vegetais parece estar relacionado aos fatores da expressão mamária alterada do gene ou do potencial da atividade enzimática.

Fernandes et al. (2008), também, relataram influência na utilização de óleos de algodão ou girassol, observando que a adição na dieta diminuiu a quantidade de ácidos graxos de cadeia curta, como mirístico, que pode proporcionar sérios problemas à saúde. Já o óleo de girassol a 5\% na matéria seca aumentou a concentração de ácidos graxos poliinsaturados, principalmente $\mathrm{o}$ linolênico, que pode tornar o leite um produto melhor para o consumo humano, tendo em vista o provável efeito deste ácido graxo na prevenção de problemas cardiovasculares. 
Maia et al. (2006) quando incluíram óleos de arroz, soja e canola em dietas para cabras lactantes, verificaram uma redução nos ácidos graxos de cadeia curta, entre eles, o ácido láurico e o mirístico, que tornam o leite de fácil digestão, em razão da ação mais eficaz das lipases ésteres dos triglicerídeos desses ácidos graxos (Park, 1994). Estes autores observaram ainda que quanto maior a concentração do C18:2 na dieta, maiores são as chances de elevar a concentração de CLA na gordura do leite. As fontes de óleo (soja e palmiste) na dieta de cabras Saanen em lactação influenciaram no aumento no teor do ácido linoléico conjugado (Bomfim et al., 2011).

A quantidade de ácidos graxos transferidos da dieta para a gordura do leite está diretamente relacionada ao nível de proteção implementado à fonte suplementar de óleo e ao tipo de suplemento empregado. Portanto, a manipulação da dieta de cabras leiteiras, dependendo do objetivo proposto para o produto final, pode ser uma forma de controlar as características nutricionais e/ou físico-químicas da gordura do leite (Gulati et al., 1997).

Para cadeia produtiva da caprinocultura leiteira a modificação do perfil dos ácidos graxos e, em especial aumento do CLA (cis-9, trans-11), molécula considerada com potencial funcional, pode ser uma estratégia utilizada para ampliar as oportunidades do mercado do leite e derivados pela agregação de valor diante ao novo consumidor preocupado com a saúde e em consumir alimentos saudáveis.

\section{Considerações finais}

Ampliar o mercado do leite de cabra implica necessariamente em agregar valor ao leite e derivados. Dessa forma, contribuir para o fortalecimento de toda cadeia produtiva da caprinocultura. A alimentação dos caprinos leiteiros pode ser uma aliada importante para a manipulação da produção e o perfil de ácidos graxos do leite através da utilização de fontes de lipídios que aumentam de forma natural o CLA (cis - 9, trans- 11) um tipo de isômero reconhecido pelos seus efeitos anticarcinogênicos e antiaterogênicos, o que torna o consumo de leite vantajoso para o consumidor pelos seus benefícios a saúde, pelo seu efeito funcional, além de nutrir, trazem benefícios metabólicos e fisiológicos a saúde humana.

\section{Referências Bibliográficas}

ANVISA. 2010. Farmacopeia Brasileira, 5 edn. Agência Nacional de Vigilância Sanitária e Fundação Oswaldo Cruz, Brasília.

Bernard, L., Shingfield, K. J., Rouel, J., Ferlay, A. \& Chilliard, Y. 2009. Effect of plant oils in the diet on performance and milk fatty acid composition in goats fed diets based on grass hay or maize silage. British Journal of Nutrition, 101, 213-224.

Bessa, R. J. B., Santos-Silva, J., Ribeiro, J. \& Portugal, A. V. 2000. Reticulo-rumen biohydrogenation and the enrichment of ruminant edible products with linoleic acid conjugated isomers. Livestock Production Science, 63, 201-211.

Bomfim, M. A. D., Queiroga, R. C. E., Aguila, M. B., Medeiros, M. C., Fisberg, M., Rodrigues, M. T., Santos, K. M. O. \& Lanna, D. P. D. 2011. Abordagem multidisciplinar de P, D\&I para o desenvolvimento de produto lácteo caprino com alto teor de CLA e alegação de propriedade funcional. Revista Brasileira de Zootecnia, 40, 98-106.

Chilliard, Y., Ferlay, A., Rouel, J. \& Lamberet, G. 2003. A review of nutritional and physiological factors affecting goat milk lipid synthesis and lipolysis. Journal of Dairy Science, 86, 1751-1770.

Cordeiro, P. \& Cordeiro, G. 2006. Mercado do leite de cabra e de seus derivados. Ver. $C F$ $M V, 39,19-23$.

Corl, B. A., Baumgard, L. H., Dwyer, D. A., Griinari, J. M., Phillips, B. S. \& Bauman, D. E. 2001. The role of $\Delta$ 9-desaturase in the production of cis-9, trans-11 CLA. The Journal of Nutritional Biochemistry, 12, 622630.

Corradini, S. A. S., Madrona, G. S., Souza, N. E., Bonafé, E. G., Carvalho, C. B. \& Prado, I. N. 2013. Sensorial characteristics and fatty acid mozzarella cheese from milk of crossbred cows fed with palm oil and coconut fat. Acta Scientiarum.Technology, 35, 789-795.

Corradini, S. A. S., Madrona, G. S., Visentainer, J. V., Bonafé, E. G., Carvalho, C. B., Roche, P. M. \& Prado, I. N. 2014. Sensorial and fatty acid profile of ice cream manufactured with milk of crossbred cows fed with palm oil and coconut fat. Journal of Dairy Science, 97, 1-9.

Delacroix-Buchet, A. \& Lamberet, G. 2000. Sensorial properties and typicity of goat dairy 
products. International Association of Goat. Proceedings of the International Conference of Goats. Tours - France.

Demeyer, D. \& Doreau, M. 1999. Targets and procedures for altering ruminant meat and milk lipids. Proceedings of the Nutrition Society, 58, 593-608.

Eifert, E. C., Lana, R. d. P., Lanna, D. P. D., Teixeira, R. M. A., Arcuri, P. B., Leão, M. I., Oliveira, M. V. M. \& Valadares Filho, S. C. 2006. Perfil de ácidos graxos e conteúdo de ácido linoléico conjugado no leite de vacas alimentadas com a combinação de óleo de soja e fontes de carboidratos na dieta. Revista Brasileira de Zootecnia, 35, 1829-1837.

Fernandes, M. F., Queiroga, R. d. C. R., Medeiros, A. N., Costa, R. G., Bomfim, M. A. D. \& Braga, A. A. 2008. Physico-chemical characteristics and fatty acid profile of milk of crossbred Moxotó goats supplemented with cottonseed or sunflower oil. Revista Brasileira de Zootecnia, 37, 703-710.

Griinari, J., Nurmela, K., Dwyer, D., Barbano, D. \& Bauman, D. 1999. Variation of milk fat concentration of conjugated linoleic acid and milk fat percentage is associated with a change in ruminal biohydrogenation. Journal of Animal Science, 77, 117-118.

Gulati, S., Byers, E., Byers, Y., Ashes, J. \& Scott, T. 1997. Effect of feeding different fat supplements on the fatty acid composition of goat milk. Animal Feed Science and Technology, 66, 159-164.

Harvatine, K., Boisclair, Y. \& Bauman, D. 2009. Recent advances in the regulation of milk fat synthesis. Animal, 3, 40-54.

Ip, C., Chin, S. F., Scimeca, J. A. \& Pariza, M. W. 1991. Mammary cancer prevention by conjugated dienoic derivative of linoleic acid. Cancer Research, 51, 6118-6124.

Jenkins, T. \& McGuire, M. 2006. Major advances in nutrition: impact on milk composition. Journal of Dairy Science, 89, 1302-1310.

Jenkins, T. C. 1993. Lipid metabolism in the rumen. Journal of Dairy Science, 76, 38513863.

Jenness, R. 1980. Composition and characteristics of goat milk: review 1968-
1979. Journal of Dairy Science, 63, 16051630.

Kepler, C. R., Hirons, K. P., McNeill, J. \& Tove, S. 1966. Intermediates and products of the biohydrogenation of linoleic acid by Butyrivibrio fibrisolvens. Journal of Biological Chemistry, 241, 1350-1354.

Khiaosa-Ard, R., Bryner, S., Scheeder, M., Wettstein, H.-R., Leiber, F., Kreuzer, M. \& Soliva, C. 2009. Evidence for the inhibition of the terminal step of ruminal $\alpha$-linolenic acid biohydrogenation by condensed tannins. Journal of Dairy Science, 92, 177-188.

Kozloski, G. V. 2011. Bioquímica dos ruminantes, 3a Ed. edn. Editora Universidade Federal de Santa Maria, Santa Maria.

Lee, K. N., Kritchevsky, D. \& Parizaa, M. W. 1994. Conjugated linoleic acid and atherosclerosis in rabbits. Atherosclerosis, 108, 19-25.

Maia, F. J., Branco, A. F., Mouro, G. F., Coneglian, S. M., Santos, G. T., Minella, T. F. \& Guimarães, K. C. 2006. Inclusão de fontes de óleo na dieta de cabras em lactação: digestibilidade dos nutrientes e parãmetros ruminais e sangüíneos. Revista Brasileira de Zootecnia, 35, 1496-1503.

Maia, M. R., Chaudhary, L. C., Bestwick, C. S., Richardson, A. J., McKain, N., Larson, T. R., Graham, I. A. \& Wallace, R. J. 2010. Toxicity of unsaturated fatty acids to the biohydrogenating ruminal bacterium, Butyrivibrio fibrisolvens. BioMed Central Microbiology, 10, 2-10.

Neves, C. A., Santos, W. B. R., Santos, G. T. D., Silva, D. C., Jobim, C. C., Santos, F. S., Visentainer, J. V. \& Petit, H. V. 2009. Production performance and milk composition of dairy cows fed extruded canola seeds treated with or without lignosulfonate. Animal Feed Science and Technology, 154, 83-92.

Onetti, S. G., Shaver, R. D., McGuire, M. A. \& Grummer, R. R. 2001. Effect of Type and Level of Dietary Fat on Rumen Fermentation and Performance of Dairy Cows Fed Corn Silage-Based Diets. Journal of Dairy Science, 84, 2751-2759.

Palmquist, D. 1989. Suplementação de lipídios para vacas em lactação. Simpósio sobre nutrição de ruminantes, $6,11-25$. 
Palmquist, D. L. \& Jenkins, T. C. 1980. Fat in lactation rations: Review. Journal of Dairy Science, 63, 1-14.

Pariza, M. W., Park, Y. \& Cook, M. E. 2001. The biologically active isomers of conjugated linoleic acid. Progress in Lipid Research, 40, 283-298.

Park, Y. W. 1994. Hypo-allergenic and therapeutic significance of goat milk. Small Ruminant Research, 14, 151-159.

Parodi, P. W. 1996. Milk fat components: possible chemopreventive agents for cancer and other diseases. Australian Journal of Dairy Technology, 51, 24-32.

Patra, A. K. \& Saxena, J. 2010. A new perspective on the use of plant secondary metabolites to inhibit methanogenesis in the rumen. Phytochemistry, 71, 1198-1222.

Sanz Sampelayo, M., Pérez, L., Martın Alonso, J., Amigo, L. \& Boza, J. 2002. Effects of concentrates with different contents of protected fat rich in PUFAs on the performance lactating Granadina goats. Small Ruminant Research, 43, 141-148.

Tamminga, S. \& Doreau, M. 1991. Lipids and rumen digestion. In: Jouany, J. P. (ed.) Rumen microbial metabolism and ruminant digestion. Institut National de la Recherche Agronomique, Paris, FR.

Tanaka, K. 2005. Occurrence of conjugated linoleic acid in ruminant products and its physiological functions. Animal Science Journal, 76, 291-303.
Toral, P. G., Hervás, G., Bichi, E., Belenguer, Á. \& Frutos, P. 2011. Tannins as feed additives to modulate ruminal biohydrogenation: Effects on animal performance, milk fatty acid composition and ruminal fermentation in dairy ewes fed a diet containing sunflower oil. Animal Feed Science and Technology, 164, 199-206.

Van Soest, P. J. 1994. Nutritional ecology of the ruminant. Cornell University Press, Ithaca, NY, USA.

Vasta, V., Makkar, H. P., Mele, M. \& Priolo, A. 2009a. Ruminal biohydrogenation as affected by tannins in vitro. British Journal of Nutrition, 102, 82-92.

Vasta, V., Mele, M., Serra, A., Scerra, M., Luciano, G., Lanza, M. \& Priolo, A. 2009b. Metabolic fate of fatty acids involved in ruminal biohydrogenation in sheep fed concentrate or herbage with or without tannins. Journal of Animal Science, 87, 26742684.

Williams, C. M. 2000. Dietary fatty acids and human health. Annales de Zootechnie. EDP Sciences.

Recebido em Janeiro 20, 2016

Aceito em Fevereiro17, 2016

License information: This is an open-access article distributed under the terms of the Creative Commons Attribution License, which permits unrestricted use, distribution, and reproduction in any medium, provided the original work is properly cited 